\title{
PENGARUH MODEL PEMBELAJARAN KOOPERATIF TIPE TEAM GAMES TOURNAMENT TERHADAP HASIL BELAJAR POKOK BAHASAN MENELADANI KETAATAN MALAIKAT- MALAIKAT ALLAH
}

\author{
Alfi Arfah, Ahmad Nizar Rangkuti, Latifa Annum Dalimunthe ${ }^{1}$ \\ nizarahmad1304@yahoo.com
}

\begin{abstract}
ABSTRAK
Tujuan penelitian ini adalah untuk mengetahui apakah terdapat pengaruh yang signifikan model pembelajaran kooperatif tipe Team Games Tournament terhadap hasil belajar pokok bahasan meneladani ketaatan malikat-malaikat Allah Swt. di kelas VII SMP Negeri 5 Padangsidimpuan. Jenis penelitian yang digunakan adalah penelitian kuantitatif dengan metode eksperimen. Populasi Penelitian ini adalah seluruh siswa kelas VII SMP Negeri 5 Padangsidimpuan. Sampel penelitian adalah siswa Kelas VII ${ }^{6}$ dan kelas VII ${ }^{7}$. Instrumen penelitian ini adalah tes belajar yang telah memenuhi kriteria valid dan reliable. Hasil penelitian ini menunjukkan bahwa terdapat pengaruh model pembelajaran kooperatif tipe Team Games Tournament terhadap hasil belajar siswa. Hal ini ditunjukkan dari hasil pengujian hipotesis dengan menggunakan uji-t diperoleh nilai $t_{\text {hitung }}>\mathrm{t}_{\text {tabel }}$ yaitu 5,91>2,060 dengan taraf signifikan 5\%. Hasil penelitian menunjukkan bahwa model pembelajaran kooperatif tipe Team Games Tournament berpengaruh secara signifikan terhadap hasil belajar siswa. Kata Kunci: Kooperatif; Team Games Tournament; Hasil Belajar
\end{abstract}

\begin{abstract}
The purpose of this study was to determine whether there was a significant influence on the type of Team Games Tournament cooperative learning model on the learning outcomes of the subject modeled on the obedience of the angels of God Almighty. in class VII of SMP Negeri 5 Padangsidimpuan. This type of research is quantitative research with experimental methods. The population of this research is all grade VII students of SMP Negeri 5 Padangsidimpuan. The research sample is students in Class VII6 and Class VII7. This research instrument is a learning test that meets valid and reliable criteria. The results of this study indicate that there is an influence of the Team Games Tournament cooperative learning model on student learning outcomes. This is indicated from the results of testing the hypothesis by using the t-test obtained tcount $>\mathrm{t}$ table that is 5.91> 2.060 with a significant level of 5\%. The results showed that the cooperative learning model Team Games Tournament had a significant effect on student learning outcomes.
\end{abstract}

Keywords: Cooperative; Team Games Tournament; Learning outcomes

\footnotetext{
${ }^{1}$ Dosen Institut Agama Islam Negeri Padangsidimpuan
} 


\section{PENDAHULUAN}

Pendidikaan adalah proses perubahan sikap dan tingkah laku seseorang atau sekelompok orang dalam usaha mendewasakan manusia melalui upaya pengajaran dan pelatihan. Dalam istilah paedagogie dapat diartikan sebagai bimbingan oleh orang dewasa secara sengaja kepada orang lain agar menjadi lebih dewasa. ${ }^{2}$

Untuk memperoleh hal yang demikian dibutuhkan suatu proses pembelajaran. Pembelajaran merupakan suatu proses yang kompleks dan melibatkan berbagai aspek yang saling berkaitan. Untuk menciptakan pembelajaran yang kreatif dan menyenangkan diperlukan berbagai keterampilan diantaranya adalah keterampilan mengelola proses pembelajaran. ${ }^{3}$

Dalam meningkatkan hasil belajar siswa dalam pembelajaran Pendidikan Agama Islam dibutuhkan model pembelajaran. Model pembelajaran pada dasarnya merupakan bentuk pembelajaran yang tergambar dari awal sampai akhir yang disajikan secara khas oleh guru. Model pembelajaran menjadi pengikat semua perangkat pembelajaran yang dibuat guru. Oleh karena itu, model pembelajaran akan mempengaruhi keberhasilan belajar peserta didik.

Pembelajaran kooperatif tipe TGT adalah salah satu pembelajaran yang melibatkan aktivitas dari seluruh siswa, proses pembelajarannya menggunakan metode tutor sebaya, dan selama prose pembelajaran penuh dengan permainan. Permainan dalam prose pembelajaran ini akan merangsang peserta didik untuk belajar sambil bermain. Dengan demikian akan tergali motivasi siswa untuk belajar.

Pembelajaran ini juga merangsang siswa agar lebih aktif berkomunikasi antara guru dengan siswa dan antara siswa dengan siswa lain selama pembelajaran berlangsung. Komunikasi ini muncul karena setiap siswa harus melakukan diskusi di setiap kelompoknya masing-masing.

Telah banyak dilakukan penelitian tentang efektivitas model pembelajaran kooperatif tipe TGT ini. Hasil penelitian Fujiyanti (2015) dan Pohan (2016) menyebutkan bahwa hasil belajar siswa pada pelajaran Fikih dengan model pembelajaraan kooperatif tipe TGT lebih baik dari pada pembelajaran konvensional. ${ }^{4}$ Oleh karena itu patut diduga bahwa model pembelajaran ini berpengaruh signifikan terhadap hasil belajar siswa.

\footnotetext{
${ }^{2}$ Hasbullah, Dasar-Dasar Ilmu Pendidikan (Jakarta: Rajawali Pers, 2011), h. 1.

${ }^{3}$ E. Mulyasa, Menjadi Guru Profesional: Menciptakan Pembelajaran Kreatif Dan Menyenangkan (Bandung: PT Remaja Rosdakarya, 2005), h. 69.

${ }^{4}$ Siti Fujiyati, "Pengaruh Model Pembelajaran Kooperatif Tipe Games Tournament (TGT) Terhadap Hasi Belajar Siswa Pada Mata Pelajaran Fiqih Di MTs Islamiyah Ciputat” (UIN Syarif Hidayatullah, 2015).
} 
Hasil wawancara yang dilakukan di SMP Negeri 5 Padangsidimpuan dengan guru mata pelajaran Pendidikan Agama Islam Mampa Luffi menyatakan bahwa model-model pembelajaran yang sering diterapkan adalah metode ceramah, tanya jawab dan diskusi. Siswa juga banyak kurang memahami mata pelajaran ini dan merasa bosan dikarenakan penyampain metode pada mata pelajaran ini sangat monoton. Jarang sekali guru menggunakan metode baru dalam menyampaikan materi ajar. Oleh karena itu, pembelajaran Pendidikan Agama Islam di SMP Negeri 5 sekolah harus merancang atau memperbaiki pelaksanaan menyampaikan metode seoptimal mungkin agar siswa dapat aktif dalam pembelajaran. Sebagai pendidik perlu adanya penguasaan ataupun penerapan untuk model-model pembelajaran agar dalam belajar akan menjadi menyenangkan dan timbul ide-baru, kreatif juga inovatif siswa.

Oleh karena itu, dilakukan penelitian dengan judul Pengaruh Model Pembelajaran Kooperatif Tipe Team Games Tournament terhadap Hasil Belajar Siswa Pokok Bahasan Meneladani Ketaatan Malaikat-Malaikat Allah Swt. di Kelas VII SMP Negeri 5 Padangsidimpuan. Peneliti melakukan penelitian ini bertujuan untuk melihat adanya pengaruh melalui model pembelajaran kooperatif tipe Team Games Tournament (TGT) dapat meningkatkan hasil belajar siswa kelas VII di SMP Negeri 5 Padangsidimpuan.

\section{METODE PENELITIAN}

Jenis penelitian ini adalah penelitian kuantitatif dengan menggunakan metode eksperimen. Penelitian eksperimen merupakan penelitian yang dimaksudkan untuk mengeahui tidaknya akibat dari "sesuatu" yang dikenakan pada subjek selidik. ${ }^{5}$ Penelitian Eksperimen juga merupakan kegiatan penelitian yang bertujuan untuk menilai pengaruh suatu perlakuan /tindakan/treatment terhadap tingkah laku suatu objek atau menguji hipotesis tentang adatidaknya pengaruh tindakan itu bila itu dibandingkan dengan tindakan lain. ${ }^{6}$ Tempat Penelitian ini adalah SMP Negeri 5 Padangsidimpuan. Penelitian dilaksanakan mulai bulan september 2018 sampai dengan bulan Mei 2019.

\footnotetext{
${ }^{5}$ Suharsimi Arikunto, Manajemen Penelitian (Jakarta: PT. Rineka Cipta, 2013), h. 207.

${ }^{6}$ Ahmad Nizar Rangkuti, Metode Penelitian Pendidikan Pendekatan Kuantitafi, Kualitatif, PTK, Dan Penelitian Pengembangan (Bandung: Citaputaka Media, 2016), h. 75.
} 
Penelitian dengan menggunakan metode eksperimen ini dalam pemecahan masalahnya adalah dengan cara mengungkapkan hubungan sebab akibat dua variabel atau lebih melalui percobaan yang cermat. ${ }^{7}$

Dalam penelitian ini peneliti menggunakan desain non randomized control group pre test pos test design, yaitu:

\begin{tabular}{|c|c|c|c|}
\hline Kelompok & Pretes & Perlakuan & Postes \\
\hline Eksprimen & $\mathrm{T}_{1}$ & $\mathrm{X}$ & $\mathrm{T}_{2}$ \\
\hline Control & $\mathrm{T} 3$ & - & $\mathrm{T}_{4}$ \\
\hline
\end{tabular}

Ket:

$\mathrm{T}_{1}=$ nilai pretest kelas eksperimen

$\mathrm{T}_{2}=$ nilai postest kelas eksperimen

$\mathrm{X}=$ diberikan berlakuan dalam jangka waktu tertentu.

$-=$ tidak diberikan perlakuan

$\mathrm{T}_{3}=$ nilai pretes kelas kontrol

$\mathrm{T}_{4}=$ nilai postest kelas kontrol

Terdapat dua kelas yang digunakan. Satu kelas berperan sebagai kelas eksperimen dimana di kelas eksperimen diberikan pembelajaran dengan menggunakan model pembelajaran tipe Team Games Tournament (TGT) kemudian satu lagi berperan sebagai kelas kontrol. Dalam kelas kontrol proses pembelajaran dilakukan secara konvesional.

Populasi dalam penelitian ini adalah seluruh siswa kelas VII SMP Negeri 5 Padangsidimpuan yang berjumlah 276 terdiri dari 9 kelas VII ${ }^{1}$ sampai dengan kelas VII ${ }^{9}$. Teknik pemilihan sampel yang dilakukan peneliti dengan clustrer sampling dengan cara teknik penentuan sampel kelompok Sampel dalam penelitian ini adalah siswa kelas VII ${ }^{6}$ yang terdiri dari 27 orang sebagai kelas kontrol dan kelas VII $^{7}$ terdiri dari 27 orang sebagai kelas eksperimen.

Penelitian ini menggunakan instrumen tes hasil belajar Pendidikan Agama Islam pada materi meneladani ketaatan malaikat Allah. INstrumen yang digunakan adalah tes pilihan ganda sebanyak 20 soal. Tes yang diberikan kepada kelas eksperimen dan kelas kontrol akan diberikan dengan tes yang sama. Setiap sampel yang diberikan soal pre-test (tes awal) dan post-test (tes akhir) pada pokok bahasan materi yang yang ditentukan dalam penelitian yang sesuai dengan

${ }^{7}$ Sofyan Siregar, Statistika Deskriptif Untuk Penelitian Dilengkapi Perhitungan Manual Dan Aplikasi SPPS Versi 17 (Jakarta: Raja Grafindo Persada, 2012), h. 108. 
susunan pada silabus. Soal pilihan ganda memuat aspek-aspek kemampuan siswa atau indikator pencapaian siswa dalam pembelajaran.

\section{HASIL PENELITIAN}

\section{Hasil Pre-Test Kelas Eksperimen dan Kontrol}

Data Pre-test kelas Eksperimen di deskripsikan untuk memperoleh gambaran tentang karakteristik variabel penelitian. Deskripsi data menyajikan nilai maksimum, nilai minimum, rentang, serta ukuran tendensi sentral.

\section{Tabel 1}

\section{Distribusi Kelompok Pre-test Eksperimen}

\begin{tabular}{|l|l|}
\hline Distribusi & Nilai \\
\hline Nilai Maksimum & 80 \\
\hline Nilai Minimum & 35 \\
\hline Rentangan & 45 \\
\hline Banyak Kelas & 6 \\
\hline Panjang Kelas & 8 \\
\hline Mean & 56.87 \\
\hline Standar Deviasi & 12.09 \\
\hline Jumlah Sampel & 27 \\
\hline
\end{tabular}

Nilai yang didapatkan pada saat pre test untuk kelas eksperimen dapat dilihat pada histogram berikut ini.

\section{Diagram 1}

Histogram Nilai Pre-Test Kelas Eksperimen

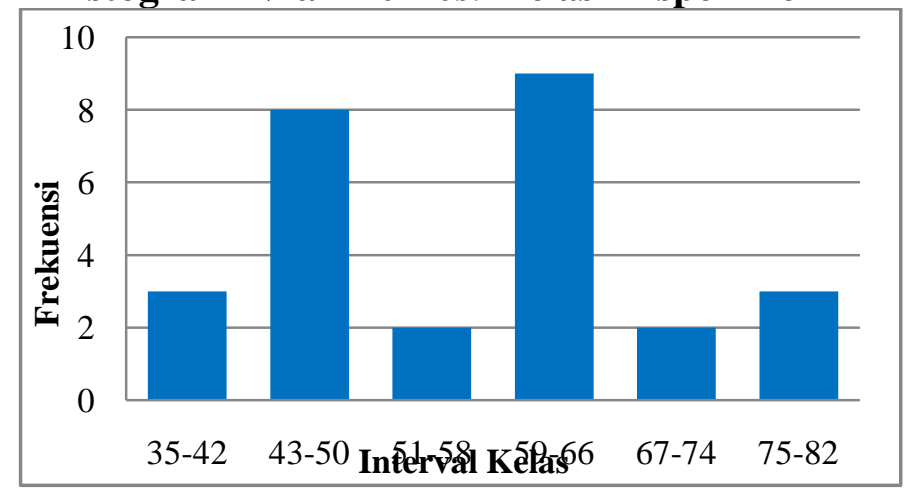

Diagram di atas menjelaskan bahwa nilai rata-rata siswa adalah 56,87. Siswa yang memperoleh hasil tes tertinggi dengan nilai interval 75-82 ada 3 orang. 
Sedangkan siswa yang memperoleh hasil tes terendah ada 3 orang dengan nilai interval 35-42.

Data Pre-test kelas Kontrol dideskripsikan untuk memperoleh gambaran tentang karakteristik variabel penelitian. Deskripsi data menyajikan nilai maksimum, nilai minimum, rentang, serta ukuran tendensi sentral.

Tabel 2

Distribusi Kelompok Pre-test Kontrol

\begin{tabular}{|l|l|}
\hline Distribusi & Nilai \\
\hline Nilai Maksimum & 80 \\
\hline Nilai Minimum & 35 \\
\hline Rentangan & 45 \\
\hline Banyak Kelas & 6 \\
\hline Panjang Kelas & 8 \\
\hline Mean & 57.76 \\
\hline Standar Deviasi & 12.17 \\
\hline Jumlah Sampel & 27 \\
\hline
\end{tabular}

Nilai yang didapatkan pada saat pre test untuk kelas kontrol dapat dilihat pada histogram berikut ini.

Diagram 2

Histogram Nilai Pre-Test Kelas Kontrol

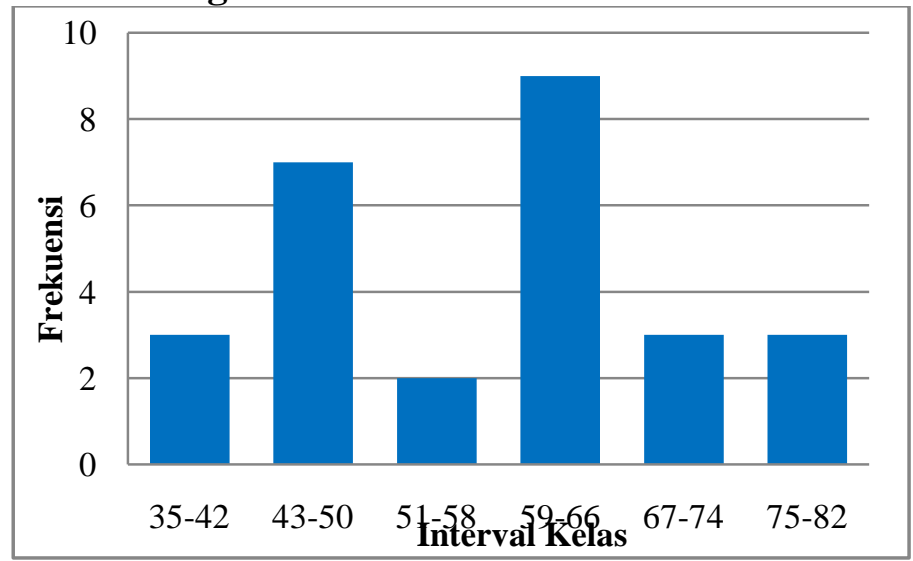

Diagram di atas menjelaskan bahwa nilai rata-rata siswa adalah 57,76. Siswa yang memperoleh hasil tes tertinggi dengan nilai interval 75-82 ada 3 orang. Sedangkan siswa yang memperoleh hasil tes terendah ada 3 orang dengan nilai interval 35-42. 


\section{Hasil Nilai Post-Test Eksperimen dan Post-Test Kontrol}

Data Post-test Eksperimen di deskripsikan untuk memperoleh gambaran tentang karakteristik variable penelitian. Deskripsi data menyajikan nilai maksimum, nilai minimum, rentang, serta ukuran tendensi sentral.

\section{Tabel 3}

Distribusi Kelompok Post-test Eksperimen

\begin{tabular}{|l|l|}
\hline \multicolumn{1}{|c|}{ Distribusi } & Nilai \\
\hline Nilai Maksimum & 100 \\
\hline Nilai Minimum & 55 \\
\hline Rentangan & 45 \\
\hline Banyak Kelas & 6 \\
\hline Panjang Kelas & 8 \\
\hline Mean & 78.87 \\
\hline Standar Deviasi & 11.52 \\
\hline Jumlah Sampel & 27 \\
\hline
\end{tabular}

Nilai yang didapatkan pada saat post test untuk kelas eksperimen dapat dilihat pada histogram berikut ini.

Diagram 3

Histogram Nilai Post-Test Kelas Eksperimen

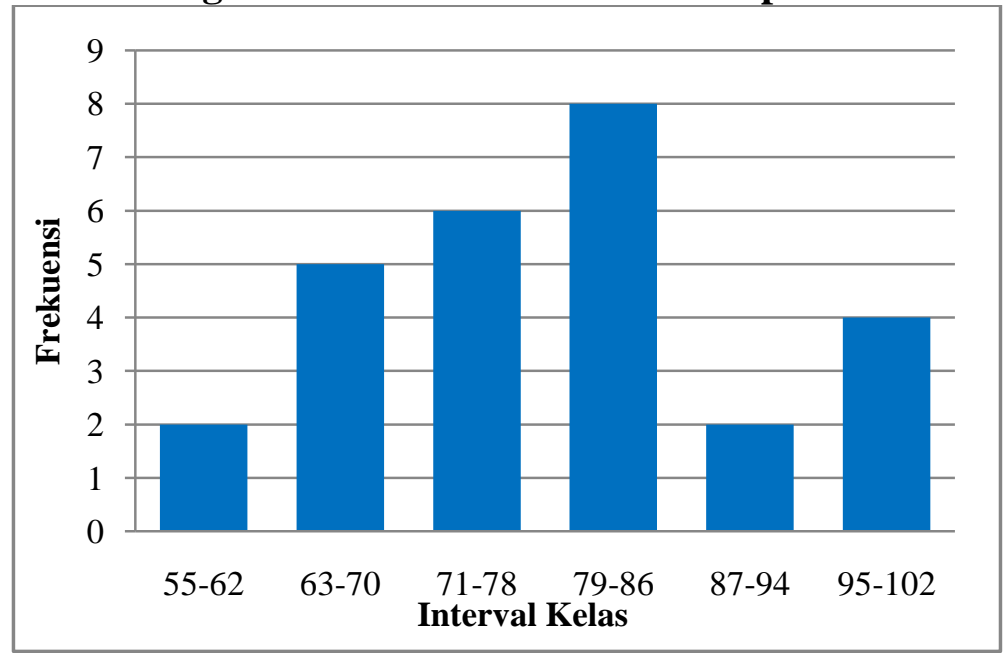

Diagram di atas menjelaskan bahwa diperoleh nilai rata-rata siswa adalah 78,87.

Siswa yang memperoleh hasil tes tertinggi dengan nilai interval 95-102 ada 4 orang. Sedangkan siswa yang memperoleh hasil tes terendah ada 2 orang dengan nilai interval 55-62 
Data Post-test kelas Kontrol di deskripsikan untuk memperoleh gambaran tentang karakteristik variabel penelitian. Deskripsi data menyajikan nilai maksimum, nilai minimum, rentang, serta ukuran tendensi sentral.

Tabel 4

Distribusi Kelompok Post-test Kontrol

\begin{tabular}{|l|r|}
\hline Distribusi & \multicolumn{1}{|l|}{ Nilai } \\
\hline Nilai Maksimum & 80 \\
\hline Nilai Minimum & 35 \\
\hline Rentangan & 45 \\
\hline Banyak Kelas & 6 \\
\hline Panjang Kelas & 8 \\
\hline Mean & 59.54 \\
\hline Standar Deviasi & 12.15 \\
\hline Jumlah Sampel & 27 \\
\hline
\end{tabular}

Nilai yang didapatkan pada saat post test untuk kelas kontrol dapat dilihat pada histogram berikut ini.

\section{Diagram 4}

\section{Histogram Nilai Post-Test Kelas Kontrol}

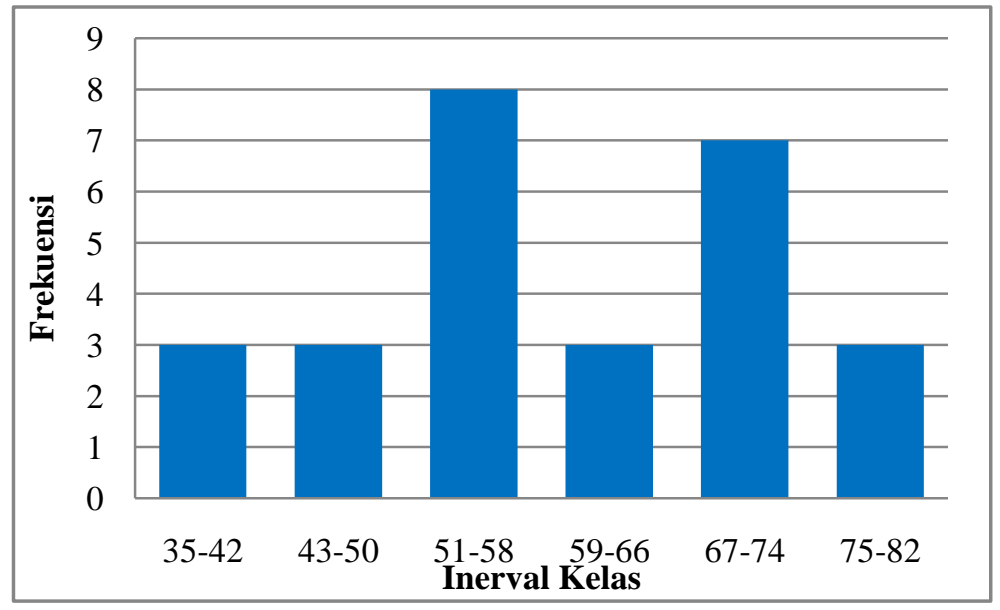

Diagram di atas menjelaskan bahwa diperoleh nilai rata-rata siswa adalah 57,76.

Siswa yang memperoleh hasil tes tertinggi dengan nilai interval 75-82 ada 3 orang. Sedangkan siswa yang memperoleh hasil tes terendah ada 3 orang dengan nilai interval 35-42. 
Data postest menunjukkan bahwa kedua kelas eksperimen dan kelas kontrol memperoleh nilai rata-rata nilai yang berbeda. Perbedaan nilai yang dioperoleh kedua kelas dapat dilihat melalui histogram berikut:

Diagram 5.

Histogram Nilai Hasil Belajar Siswa

Kelas Eksperimen dan Kontrol

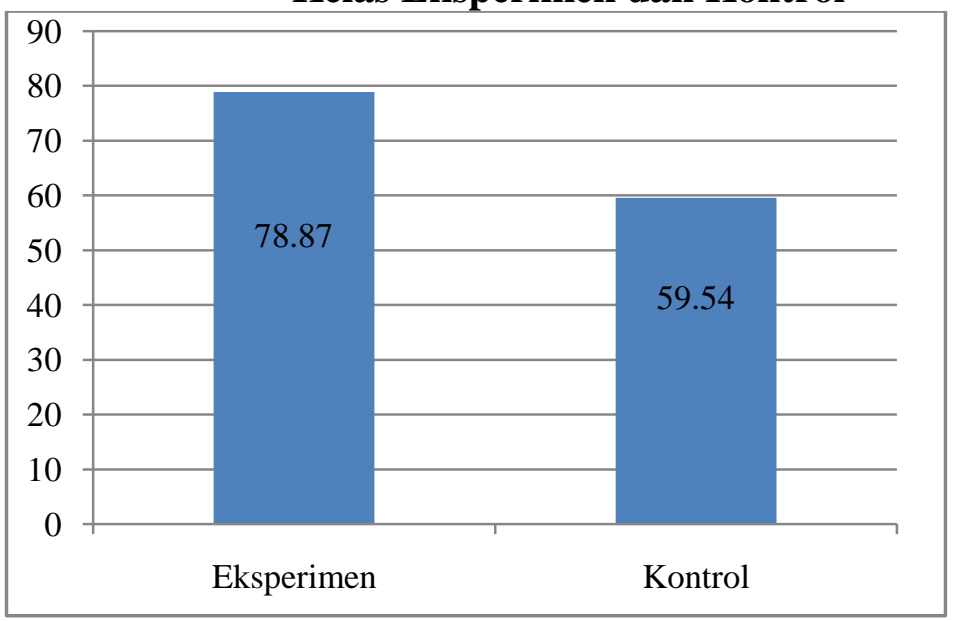

\section{Pengujian Persyaratan Analisis}

\section{a. Uji Persyaratan Analisis Data Awal (Pretest)}

\section{1) Pengujian Normalitas}

Untuk mengukur suatu tingkat kenormalan data diperlukan yang namanya uji normalitas data yang digunakan. Suatu data yang dianggap normal dilihat apabila $\chi_{\text {hitung }}<\chi_{\text {tabel. }}$ Perhitungan uji normalitas digunakan rumus Chi-Kuadrat. Hasil perhitungan pada uji normalitas terdapat pada tabel berikut:

Tabel 5

Hasil Uji Normalitas Data Awal Pre-Test

\begin{tabular}{|l|c|c|c|c|c|}
\hline Variabel & $\begin{array}{c}\text { Jumlah } \\
\text { Sampel }\end{array}$ & $\begin{array}{c}\text { Taraf } \\
\text { Signifikan }\end{array}$ & $\begin{array}{c}\mathrm{X}_{\text {hitung }} \\
\left(\mathrm{X}_{\mathrm{h})}\right.\end{array}$ & $\begin{array}{c}\mathrm{X}_{\text {tabel }} \\
\left(\mathrm{X}_{\mathrm{t})}\right.\end{array}$ & Keterangan \\
\hline $\begin{array}{l}\text { Pretest } \\
\text { Eksperimen }\end{array}$ & 27 & 0,05 & 6,86 & 7,82 & Normal \\
\hline $\begin{array}{l}\text { Pretest } \\
\text { Kontrol }\end{array}$ & 27 & 0,05 & 4,98 & 7,82 & Normal \\
\hline
\end{tabular}




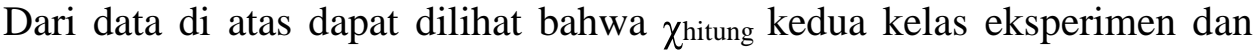
kontrol lebih kecil dari $\chi_{\text {tabel }}$ dengan $\mathrm{dk}=\mathrm{k}-3=6-3=3$, sehingga disimpulkan bahwa kedua kelas hasil dari data awal (pretest) berdistribusi normal.

\section{2) Uji Homogenitas Varians}

Kriteria yang digunakan dalam uji homogenitas berlaku jika $F_{\text {hitung }} \geq F_{\text {tabel }}$ berarti tidak homogen, dan jika $F_{\text {hitung }} \leq F_{\text {tabel }}$ berarti homogen. Di bawah ini adalah hasil perhitungan uji homogenitas data pretes.

Tabel 6.

Uji Homogenitas Varians Pre-Test

\begin{tabular}{|c|c|c|c|c|c|}
\hline \multicolumn{2}{|c|}{ Variansi } & $\begin{array}{c}\text { Taraf } \\
\text { Signifikansi }\end{array}$ & $F_{\text {hitung }}$ & $F_{\text {tabel }}$ & Ket. \\
\cline { 1 - 2 } E & K & 0.05 & 1,01 & 2,68 & Homogen \\
\cline { 1 - 2 } 150 & 148,79 & & & & \\
\hline
\end{tabular}

Dari hasil perhitungan diperoleh nilai variansi pretest kelas eksperimen 150 dan varians pretest kelas kontrol adalah 148,79 sehingga diperoleh nilai $F_{\text {hitung }}=1,01$ dengan taraf signifikansi $a=0,05$ untuk dk pembilang $(k-1)=5$ dan dk penyebut $(n-k)=21$ maka dapat diketahui $F_{\text {tabel }}=2,68$, dan diketahui $F_{\text {hitung }}=$ 1,01. Maka homogenitas pada pretest kelas kontrol dan eksperimen 1,01< 2,68 dari $\mathrm{F}_{\text {tabel}}$, sehingga $\mathrm{H}_{\mathrm{o}}$ diterima. Jadi kelas sampel yaitu kelas ekperimen dan kontrol data pretes adalah mempunyai varians yang sama atau homogen.

Untuk melihat perbedaan rata-rata dari kedua kelompok, dilakukan dengan menggunakan uji-t. Selanjutnya dapat dilihat pada tabel 7 berikut ini.

\section{Tabel 7.}

\section{Uji Perbedaan Dua Rata-Rata}

\begin{tabular}{|c|c|c|c|c|c|}
\hline Kelompol & $\mathrm{N}$ & Mean & $S_{1}^{2}$ & \multirow{2}{*}{$\mathrm{t}_{\text {hitung }}$} & $\mathrm{t}_{\text {tabel }}$ \\
\cline { 1 - 4 } $\mathrm{E}$ & 27 & 56,8 & 150 & \multirow{2}{*}{1,06} & \multirow{2}{*}{2,06} \\
\cline { 1 - 4 } $\mathrm{K}$ & 27 & 57,76 & 148,79 & & \\
\hline
\end{tabular}

Dari data diatas dapat disimpulkan bahwa $1,06<2,06$ yang berarti kedua kelompok sampel tersebut tidak berbeda secara signifikan. Dari analisis ini disimpulkan bahwa kedua kelompok kelas ini berasal dari data yang berdistribusi normal. Selain itu, kedua data tersebut juga terdistribusi secara heterogen. 


\section{b. Uji Persyaratan Analisis Data Akhir (Postest)}

\section{1) Pengujian Normalitas}

Untuk mengukur suatu tingkat kenormalan data diperlukan yang namanya uji normalitas data yang digunakan. Suatu data yang dianggap normal dilihat apabila $\chi_{\text {hitung }}<\chi_{\text {tabel. }}$ Perhitungan uji normalitas digunakan rumus Chi-Kuadrat. Hasil perhitungan pada uji normalitas terdapat pada tabel berikut:

Tabel 8.

Hasil Uji Normalitas Post-Test

\begin{tabular}{|l|c|c|c|c|c|}
\hline & $\begin{array}{c}\text { Jumlah } \\
\text { Sampel }\end{array}$ & $\begin{array}{c}\text { Taraf } \\
\text { Signifikansi }\end{array}$ & $\begin{array}{c}\mathrm{X}_{\text {hitung }} \\
\left(\mathrm{X}_{\mathrm{h}}\right.\end{array}$ & $\begin{array}{c}\mathrm{X}_{\text {tabel }} \\
\left(\mathrm{X}_{\mathrm{h})}\right.\end{array}$ & Ket \\
\hline $\begin{array}{l}\text { Post tes } \\
\text { Eksperimen }\end{array}$ & 27 & 0,05 & 4,98 & 7,82 & Normal \\
\hline $\begin{array}{l}\text { Post test } \\
\text { Kontrol }\end{array}$ & 27 & 0,05 & 3,77 & 7,82 & Normal \\
\hline
\end{tabular}

Dari data diatas dapat dilihat bahwa $\chi$ hitung kedua kelas eksperimen dan kontrol lebih kecil dari $\chi_{\text {tabel }}$ dengan $\mathrm{dk}=\mathrm{k}-3=6-3=3$, sehingga disimpulkan bahwa kedua kelas hasil dari data akhir (postest) berdistribusi normal.

\section{a. Uji Homogenitas Varians}

Uji Homogenitas yang dilakukan apabila $F_{\text {hitung }} \geq F_{\text {tabel }}$ berarti tidak homogen, dan jika $F_{\text {hitung }} \leq \mathrm{F}_{\text {tabel }}$ berarti homogen. Dibawah ini adalah hasil perhitungan uji homegenitas data pos test.

\section{Tabel 9.}

Hasil Uji Homogenitas Post-Test

\begin{tabular}{|c|c|c|c|c|l|}
\hline \multicolumn{2}{|c|}{ Varians } & $\begin{array}{l}\text { Taraf } \\
\text { Signifikan }\end{array}$ & $F_{\text {hitung }}$ & $F_{\text {tabel }}$ & Ket. \\
\hline Eksperimen & Kontrol & 0.05 & 1.09 & 2,68 & Homogen \\
\hline 138,46 & 150,64 & & & & \\
\hline
\end{tabular}

Data diperoleh nilai varians post-test kelas eksperimen 138,46 dan nilai varians post-test kelas kontrol 150,64 dengan taraf signifikan $\mathrm{a}=0,05$ untuk $\mathrm{dk}$ pembilang $(\mathrm{k}-1)=5$ dan $\mathrm{dk}$ penyebut $(\mathrm{n}-\mathrm{k})=21$ maka didapat $\mathrm{F}_{\text {tabel }}=2,68$ maka karena $\mathrm{F}_{\text {hitung }}=1,09$ pada postest kelas kontrol dan eksperimen $1,09<2,68$ dari 
$\mathrm{F}_{\text {tabel }}$ maka $\mathrm{H}_{\mathrm{o}}$ diterima. Artinya kedua kelas eksperimen dan kontrol setelah dilakukan model pempelajaran Team Games ournament (TGT) dan pembelajaran biasa masih mempunyai varians yang sama.

\section{3) Uji Hipotesis}

Setelah diberikan perlakuan terhadap kedua kelas kontrol dan eksperimen bahwa kedua kelas berdidtribusi normal dan memiliki varians yang sama, maka dapat dilanjutkan dengan uji-t.

Keterangan:

$\mathrm{H}_{0=} \quad \mu_{1} \leq \mu_{2}$

hipotesis nol, artinya rata-rata hasil belajar siswa pada pokok bahasan meneladani ketaatan malaikat-malaikat Allah Swt. tidak lebih baik dari rata-rata hasil belajar siswa tanpa menggunakan model Team Games Tournament (TGT) .

$\mathrm{H}_{\alpha}=\mu_{1}>\mu_{2}$

Hipotesis alternatif, artinya rata-rata hasil belajar siswa pada pokok bahasan meneladani ketaatan malaikat-malaikat Allah Swt. dengan menggunakan model Team Games Tournament (TGT) lebih baik dari rata-rata hasil belajar siswa tanpa menggunakan model pembelajaran Team Games Tournament (TGT) Tournament (TGT) Untuk perhitungan hasil perhitungan hasil pengujian hipotesis, dapat dilihat pada tabel berikut:

Tabel 10.

Hasil Uji Hipotesis Kelas Eksperimen dan Kontrol

\begin{tabular}{|l|r|l|c|l|l|}
\hline Kelompol & $\mathrm{N}$ & Mean & $S_{1}^{2}$ & $\mathrm{t}_{\text {hitung }}$ & $\mathrm{t}_{\text {tabel }}$ \\
\hline Eksperimen & 27 & 59,54 & 150,64 & \multirow{2}{*}{5,9127} & \multirow{2}{*}{2,06} \\
\hline Kontrol & 27 & 78,87 & 138,46 & & \\
\hline
\end{tabular}

Berdasarkan pengujian nilai rata-rata hasil belajar Pendidikan Agama Islam pokok bahasan meneladani ketaatan Malaikat-Malaikat Allah SWT. 
diperoleh harga $t_{\text {hitung }}=5,9127$ dengan taraf signifikan $a=0,05$ dan derajat kebebasan $(\mathrm{dk}=\mathrm{n}-2)=25$ diperioleh nilai $\mathrm{t}_{\text {tabel }}=2,06$ (Perhitungan terdapat pada lampiran 17). Data yang terlihat bahwa $t_{\text {hitung }}$ berada diantara $t_{\text {tabel }}$ artinya $t_{\text {hitung }}>$ $\mathrm{t}_{\text {tabel }}$ yaitu $5,9127>2,06$ yang menunjukkan $\mathrm{H}_{\mathrm{a}}$ diterima dan $\mathrm{H}_{0}$ ditolak. Sehingga dapat disimpulkan bahwa terdapat pengaruh model pembelajaran kooperatif tipe Team Games Tournament (TGT) terhadap hasil belajar.

\section{PEMBAHASAN}

Berdasarkan hasil uji hipotesis ditemukan bahwa $\mathrm{H}_{\mathrm{o}}$ ditolak, dengan hal tersebut hipotesis alternatif $\left(\mathrm{H}_{\mathrm{a}}\right)$ menyatakan hasil belajar Pendidikan Agama Islam siswa yang diajarkan dengan menggunakan model pembelajaran Team Games Tournament (TGT) memiliki nilai rata-rata tinggi dibandingkan dengan nilai siswa yang dalam menggunakan metode teacher center pada taraf signifikan 0,05 .

Setelah model pembelajaran Team Games Tournament diterapkan pada kelas sampel eksperimen pembelajaran terlihat aktif dan menemukan banyak wawasan daripada siswa pada kelas kontrol yang menerapkan metode Teacher Center pada materi meneladani ketaatan Malaikat-Malaikat Allah SWT.

Hasil penelitian ini sejalan dengan hasil penelitian Fujiyanti (2015) yang menyebutkan bahwa hasil belajar siswa pada pelajaran Fikih dengan model pembelajaraan kooperatif tipe TGT lebih baik dari pada pembelajaran konvensional, ${ }^{8}$ Pohan (2016) yang menyebutkan terdapat peningkatan hasil belajar siswa materi zakat dengan penerapan model pembelajaran kooperatif tipe TGT. ${ }^{9}$ Dengan demikian hasil penelitian ini menguatkan hasil penelitian sebelumnya.

\section{KESIMPULAN}

Hasil penelitian yang telah dilakukan ini menyatakan bahwa terdapat pengaruh yang signifikan dari penggunaan model pembelajaran kooperatif tipe Team Games Tournament (TGT) terhadap hasil belajar Pendidikan Agama Islam siswa kelas VII. Hasil perolehan ditunjukkan dari

\footnotetext{
${ }^{8}$ Siti Fujiyati, "Pengaruh Model Pembelajaran Kooperatif Tipe Games Tournament (TGT) Terhadap Hasi Belajar Siswa Pada Mata Pelajaran Fiqih Di MTs Islamiyah Ciputat” (UIN Syarif Hidayatullah, 2015).

${ }^{9}$ Ahmad Yasir Pohan, "Implementasi Pembelajaran Kooperatif Tipe TGT Dalam Meningkatkan Motivasi Dan Hasil Belajar Pada Materi Zakat Dan Hikmahnya Di Kelas X MAS Taman Perguruan Islam (TPI) Purba Sinomba Kecamatan Padang Bolak Kabupaten Padang Lawas Utara” (Unimed, 2016).
} 
uji hipotesis yang menggunakan uji-t. Sehingga nilai yang didapat adalah $t_{\text {hitung }}=5,91$ lebih besar dari $\mathrm{t}_{\text {tabel }}=2,06$ dengan tingkat taraf signifikan 0,05 , sehingga hipotesis nol $\left(H_{0}\right)$ ditolak dan hipotesis alternative $\left(H_{a}\right)$. Selain itu, dilihat dari hasil perbandingan pre-test dan post-test, nilai rata-rata pre-test yang di dapat oleh kelas kontrol adalah 57,76 dan kelas eksperimen 56,87 kelas, sedangkan hasil nilai rata-rata post-test yang menggunakan model pembelajaran kooperatif tipe Team Games Tournament 78,87 menyatakan bahwa nilai yang terttinggi dibandingkan pada kelas kontrol yang menerapkan metode Teacher Center 59,54.

\section{REFERENSI}

Arikunto, Suharsimi. Manajemen Penelitian. Jakarta: PT. Rineka Cipta, 2013.

Fujiyati, Siti. "Pengaruh Model Pembelajaran Kooperatif Tipe Games Tournament (TGT) Terhadap Hasi Belajar Siswa Pada Mata Pelajaran Fiqih Di MTs Islamiyah Ciputat." UIN Syarif Hidayatullah, 2015.

Hasbullah. Dasar-Dasar Ilmu Pendidikan. Jakarta: Rajawali Pers, 2011.

Mulyasa, E. Menjadi Guru Profesional: Menciptakan Pembelajaran Kreatif Dan Menyenangkan. Bandung: PT Remaja Rosdakarya, 205AD.

Pohan, Ahmad Yasir. "Implementasi Pembelajaran Kooperatif Tipe TGT Dalam Meningkatkan Motivasi Dan Hasil Belajar Pada Materi Zakat Dan Hikmahnya Di Kelas X MAS Taman Perguruan Islam (TPI) Purba Sinomba Kecamatan Padang Bolak Kabupaten Padang Lawas Utara." Unimed, 2016.

Rangkuti, Ahmad Nizar. Metode Penelitian Pendidikan Pendekatan Kuantitafi, Kualitatif, PTK, Dan Penelitian Pengembangan. Bandung: Citaputaka Media, 2016.

Siregar, Sofyan. Statistika Deskriptif Untuk Penelitian Dilengkapi Perhitungan Manual Dan Aplikasi SPPS Versi 17. Jakarta: Raja Grafindo Persada, 2012. 